\title{
A Study of the Replacement of Materials in Smart Card
}

\author{
Md. Khalilur Rahman1,2*, Raphaël Marchand3, Budrun Neher² \\ ${ }^{1}$ Department of Functional Advanced Materials and Engineering, Grenoble Institute and Technology, \\ Grenoble, France \\ ${ }^{2}$ Department of Physics, Comilla University, Comilla, Bangladesh \\ ${ }^{3}$ Department of Materials Science and Engineering, Grenoble Institute and Technology, Grenoble, France \\ Email: ${ }^{*}$ khalilphys@cou.ac.bd
}

Received 29 July 2015; accepted 6 September 2015; published 9 September 2015

Copyright (C) 2015 by authors and Scientific Research Publishing Inc.

This work is licensed under the Creative Commons Attribution International License (CC BY). http://creativecommons.org/licenses/by/4.0/

(c) (i) Open Access

\section{Abstract}

Gold, nickel and copper are usually used in connector of the smart card. Since Au is expensive and $\mathrm{Ni}$ is an allergenic material, simulated (CES) and bibliographical work is carried out in order to replace the Au and Ni layer in smart card connectors without sacrificing reliability. During the work, mechanical and electrical properties, corrosion resistance, cost, toxicity and process compatibility of the samples have been taken into consideration. $\mathrm{Cu}$ alloying with $\mathrm{Zn}$ or $\mathrm{Sn}, \mathrm{Cr}$ and stainless steel were selected for electrodeposition process. Secondly, carbides (WC, TiC, ZrC), Ti, TiN, borides $\left(\mathrm{TiB}_{2}\right)$ and silicide $\left(\mathrm{MoSi}_{2}\right)$ are considered as a vapour deposited materials and some $\mathrm{Cu}$ alloying with $\mathrm{Al}, \mathrm{N}$ or $\mathrm{Mg}$ also considered via ion implantation processes. But, vapour deposition and implantation are high energy processes compared to the electrodeposition process, which is expensive. Therefore, electrodeposited materials such as, $\mathrm{Cu}$ alloys (Brass or bronze), $\mathrm{Cr}$ and stainless steel could be considered as promising candidate to replace the $\mathrm{Au}$ and Ni layer in smart card connectors.

\section{Keywords}

Mechanical and Electrical Properties, Corrosion Resistance, Cost, Process Compatibility, CES Study

\section{Introduction}

A smart card is a device aimed to simplify and make more secure transactions, communication, building access etc. It includes an integrated circuit able to store, process and encrypt data [1]. For example, the use of smart

${ }^{*}$ Corresponding author. 
cards prevented the telephone cabins from being vandalized. The world wide spread of smart cards occurred in the $90^{\text {ies }}$ and the era of mobile phone in the year 2000. But in 2014, 8 billions smart cards were produced worldwide and the growth of the market was $9 \%$, where 5.1 billion smart cards were only SIM cards [2]. A smart card includes a polyvinyl chloride body, in which a trench is made for the integrated circuit chip. The chips are mounted on Au coated connection pads lying on an adhesive film. The most common technique used is wire bounding. The chip modules are then pressed out of the film and inserted in the trench by lamination [3]. The connection pads are done on a tape substrate. They include a $\mathrm{Cu}$ foil ( $\mu \mathrm{m}$ range), coated with $\mathrm{Ni}(2-50 \mu \mathrm{m})$ and $\mathrm{Au}(\approx 50 \mathrm{~nm})$ [4]. The Au layer is aimed to protect the connection pad from corrosion, whereas the Ni layer is made to harden the assembly and to act as a diffusion barrier in order to prevent Au and Cu to mix. The use of $\mathrm{Au}$ in order to protect the connection pads from corrosion represents a high cost in the process. Moreover, it requires a Ni layer as diffusion barrier between $\mathrm{Au}$ and $\mathrm{Cu}$. Since Ni is an allergenic element, it may be forbidden in the future, because of lead. Although it is hidden by the Au layer it can go through pores of the Au layer and eventually be in contact with the consumer's hands or fingers. Then, at the end of life of smart-card because of wear of the Au layer, Ni can be directly in contact with the consumer's hand. For these two reasons it was proposed to find a new material to deposit on the top of the $\mathrm{Cu}$ foil of the connection pad. This material has the function to protect the $\mathrm{Cu}$ layer from mechanical and chemical aggression and to transmit the information between the reader and the Cu layer.

\section{Methodology}

The connection pad is the interface between the chip and the outer world. Therefore it must be able to transmit the information to the outer world and need to protect the chip from degradation. So the materials used for the coating should have good mechanical and electrical properties, good corrosion resistance and a better process compatibility. The required values of these characteristics are discussed in below using simulation (CES) and bibliographical research.

\subsection{Mechanical and Electrical Properties}

Different things are put in contact with the connection pad of a smart card during its lifetime and against the mechanical attacks the connection pad must not be impacted and wear out. Mechanical attacks are mainly: fingers contact, friction with the wallet or pocket material that can be put in the same pocket, accidental bending of the card, contact with keys and with the electrodes of the reader. The bending properties of the coating are not to be considered. Indeed in the current technology the thickness of the coating is 10 orders of magnitudes smaller than that of the substrate and cannot represent a major change in the bending properties of the pad. Therefore, the substrate of the connection pad is stiff enough to protect the chip from a uniform load or that the chip and its protective layer are strong enough to support such a load. Concerning wear resistance, need enough yield strength [5]. Indeed, for a given load, the wear rate depends on the yield strength of the surface. The thickness of the coating must be high enough in order to allow wear to some extent. However, the yield strength of a material is proportional to the hardness in a first approximation. The hardness of a minimum thickness for the coating makes it impact-proof. This minimum thickness will prevent the coating from wear during its 3 to 4 years of utilization. Concerning impact resistance, hardness is the main requirement and its measure of the impact left by a probe with a particular load. But vickers hardness (Hv) was used in Figure 1, since it is a property which is given in CES study. In order to evaluate the required values of hardness has been considered the impact left by a $200 \mathrm{~g}$ load on the coating. Bausson, S., specifies that the pad must not be impacted by a $1.5 \mathrm{~N}$ load applied on it through a $1.5 \mathrm{~mm}$ diameter steel ball [6]. Such a situation may happen when the card is tight in a pocket with a key, for example. To keep a nice appearance during the whole lifetime of the card, the depth of any impact made by such a load must be less than the thickness of the coating. Therefore, a required thickness for a given hardness of the coating was calculated, $t_{\text {critical }}=0.251 / \sqrt{ }$ (hardness), where area of the impact is $A=\pi R^{2}$. May be under these conditions the wear resistance of the coating is high enough for the 4 years of life of the smart card.

The connection pad must transmit information between the chip and the reader. This information relies on voltage values. For example, when the reader stores some data in the memory, it needs to impose a particular value of voltage to a particular output of the chip. Therefore the potential drop between the reader's electrode and this output must be low compared to the value of the voltage. In a first approximation will require the potential drop across the connection pad is of the same order of gold wire connecting pad to the chip. The resistance 


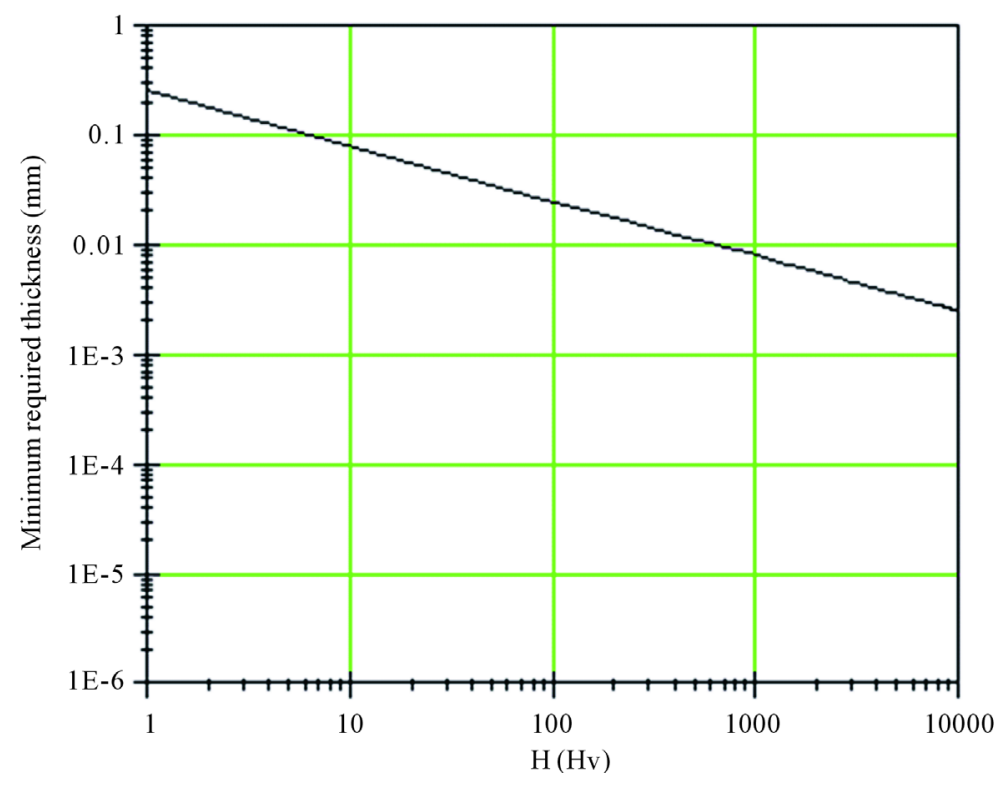

Figure 1. Required thickness for impact resistance as a function of the hardness.

of such a wire is given $5 \times 10^{-2} \Omega$ with a length $5 \mathrm{~mm}$, diameter $50 \mu \mathrm{m}$ and a resistivity of $2.2 \mu \Omega \cdot \mathrm{cm}$. The thickness of the coating is free to some extend: the minimal thickness can achieve depends on the process and on the hardness requirement. The non-realist very high value of maximum thickness obtained for metals like $\mathrm{Cu}$ and the section of conductor followed by the current in the coating is $0.25 \mathrm{~mm}^{2}$, is may be wrong. This value was estimated by approximately measuring the width of the lines left by the electrode on an old smart card. It was $0.5 \mathrm{~mm}$ wide, so the surface of the contact square was deduced around $0.25 \mathrm{~mm}^{2}$. But the contact is may be really established on a smaller part of this surface (for example because of oxide layer). If the area is considered to be the same as the section of the Au wire, there is a factor 100 and the curve becomes in Figure 2. The real limiting thickness probably lies between these two curves.

\subsection{Corrosion Resistance}

$\mathrm{Cu}$ is a material which gets corroded easily. This is the reason of the Au deposition. Indeed, the card is exposed to different oxidizing agents: oxygen and water of the atmosphere, sweat of the user (during a contact with the fingers or when it is stored in the user's pocket) and accidental contact with household chemicals. A resistance of oxygen is also required to prevent dry corrosion from the atmosphere. Since in CES study, corrosion resistance is not measured by a number. The software gives qualifications as excellent, good, acceptable or unacceptable resistance in different media. So the coating required the properties of high hardness, corrosion resistance, high conductivity, low cost, process compatibility and environmental issues.

\section{Finding Materials}

Simulated and bibliographical work in both of the cases has been tried to find a single material which could satisfy all the properties at the same time, if not possible another way to find the solution would be to have a composite material.

\subsection{Study with CES 2010 (EDUPACK)}

\subsubsection{Mechanical and Electrical Properties}

Simulated (CES) work has been started with the Vickers hardness and electrical conductivity, where hardness vs. electrical resistivity was plotted in Figure 3. A box has been drawn fixing the highest value of conductivity to 1 $\mathrm{E} 8 \mu \Omega \cdot \mathrm{cm}$ and the lowest value of hardness to $1 \mathrm{Hv}$. Level 3 of CES has been used in order to use the corrosion resistance data. 


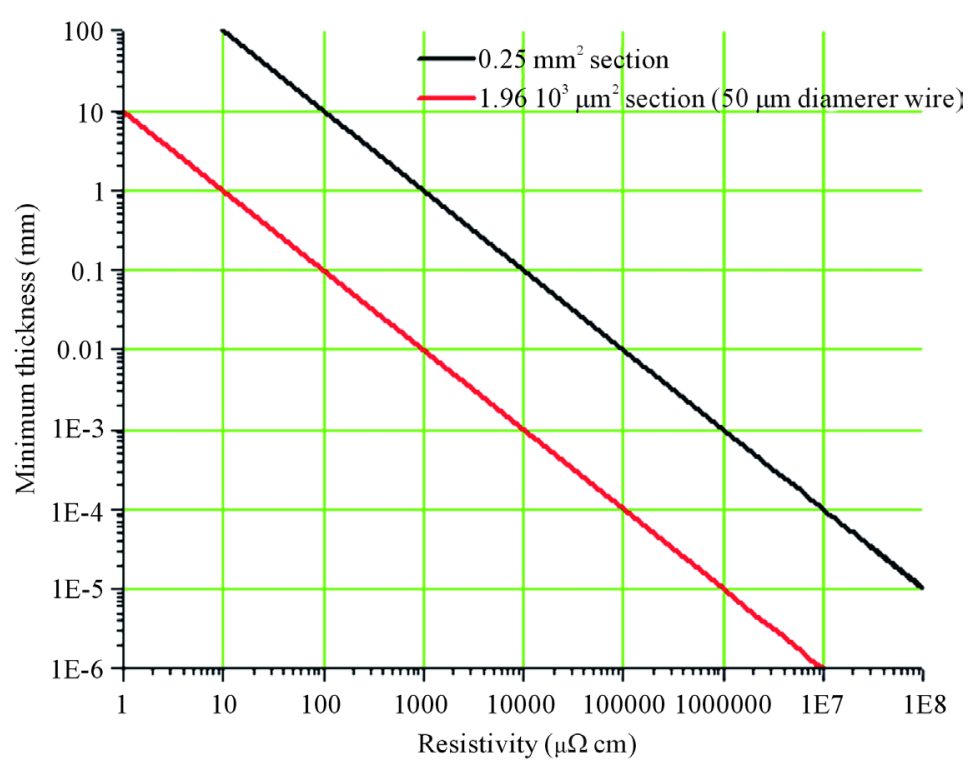

Figure 2. Maximum thickness of the film required for low resistance.

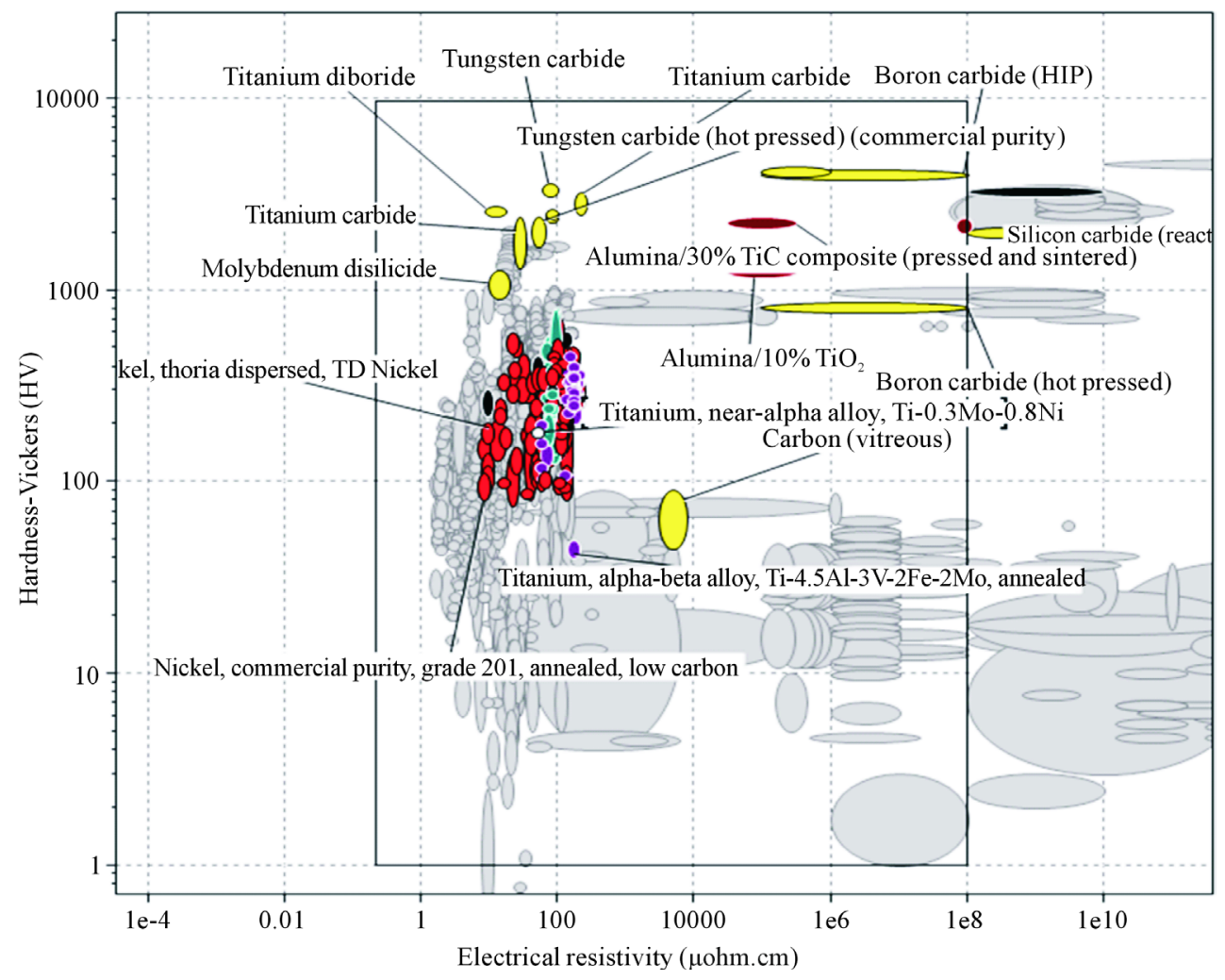

Figure 3. Hardness vs. resistivity diagram from CES.

\subsubsection{Corrosion Resistance}

At this stage, around 2000 materials were found. Now considering the corrosion properties listed in CES: Fresh water, salty water (oceanic climate and sweat), weak acids and alkalis, strong acids and alkalis were selected. The limit has been fixed for fresh water, salty water, weak acids and weak alkalis to excellent, since the exposure to these species is likely to be frequent (species in the environment, sweat, oceanic climate). Strong acids and alkalis were fixed as an acceptable resistance, since the exposure to these species is likely to be accidental, 
for example during contact with household chemicals or a hand having touched these products. Concerning dry oxidation, the materials were selected which had acceptable and excellent resistance to dry oxidation at $500^{\circ} \mathrm{C}$.

\subsubsection{Cost}

Before considering the cost around 450 materials were left. Cost is really depends on the process made to deposit the film. In CES, costs are given for bulk materials. In Figure 4 concerning the coating processes is not provided. But in the case of $\mathrm{Au}$, the most expensive is the material itself and not the deposition process. Indeed electroplating is used to deposit other metals without much expense. Using CES, materials will be eliminated considering having high bulk cost. The price of Au (commercial purity) is around 30,000 Euros/kg. But in CES studies, the higher value of cost was fixed to 100 Euros $/ \mathrm{kg}$ in order to select very low cost materials compared to $\mathrm{Au}$.

\subsubsection{List of Suitable Materials from Modeling Work}

Considering all of the cases around 300 materials are listed: Ni-Mo-Fe alloy, Ni-Fe alloy, Alumina- $\mathrm{TiO}_{2}$, Alumina-TiC composite, Alumina-B4C composite, B carbide, Carbon (vitreous), $\mathrm{Cr}$ and $\mathrm{Cr}$ alloys, Co alloys, $\mathrm{Cu}$ alloys and $\mathrm{Cu}-\mathrm{Ni}$ alloys, Hafnium, Iron-based super alloys, Metal impregnated carbon, $\mathrm{MoSi}_{2}$, Ni and Ni alloys, Nb carbide, Lead alloy, Carbon fibers, Si carbide, Ta carbide, W carbide, Zr carbide, Stainless steel, Ti, Ti carbide, $\mathrm{TiB}_{2}$, Zr, Zr alloys.

\subsection{Bibliographical Work}

Bibliographical study was carried out to find another view than the CES's one. Using the keywords; corrosion resistant, wear resistant, conductive materials, connection pads, oxide resistance, contact resistance and thickness tried to include in a more oriented view on microelectronics and contacts, in order to find some better candidate materials.

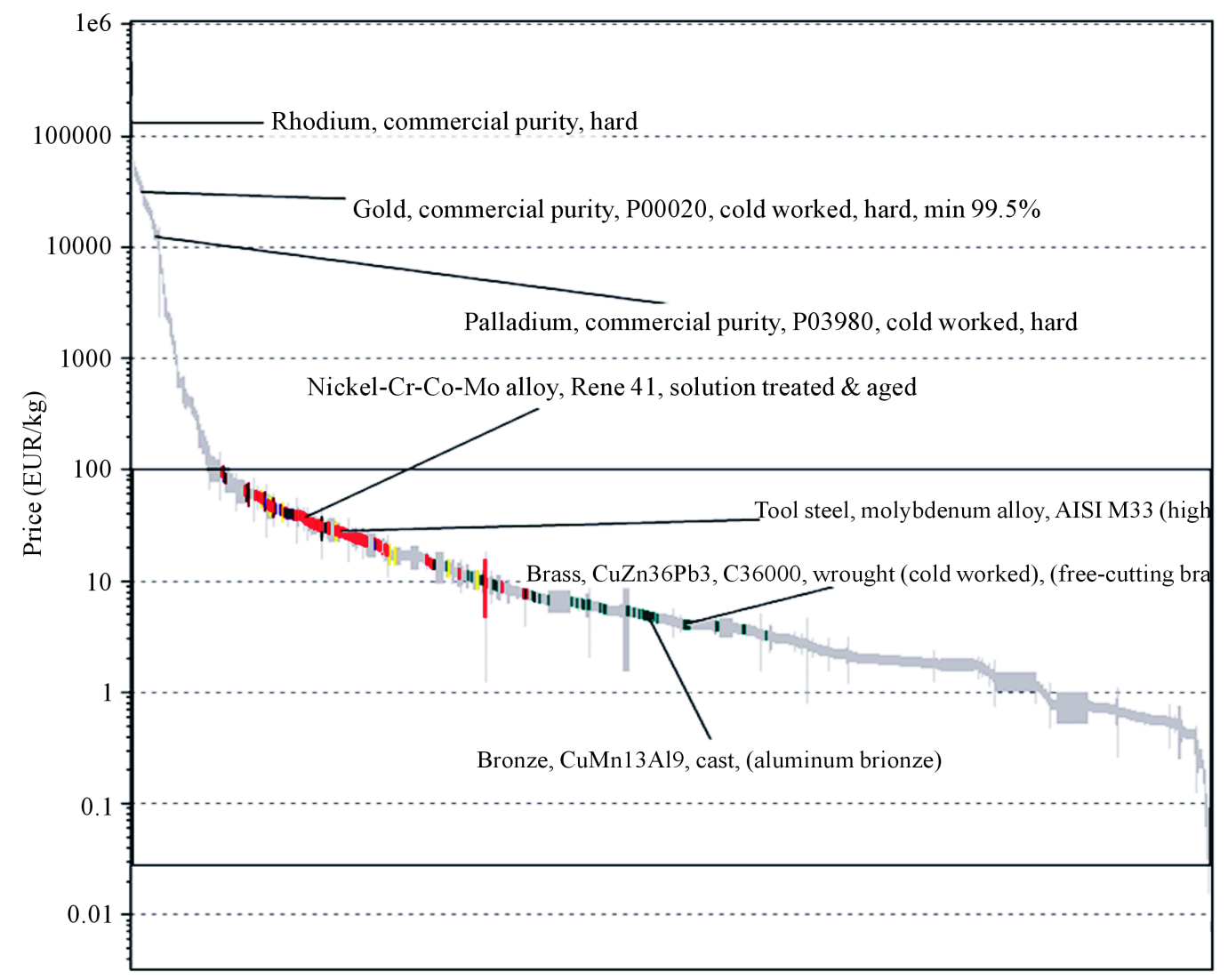

Figure 4. Bulk cost diagram from CES. 


\subsubsection{Copper $(\mathrm{Cu})$ and $\mathrm{Cu}$ Alloys}

$\mathrm{Cu}$ has bad corrosion resistance because the passive film formed [7] on its surface and is not protective enough to prevent from further corrosion. However it was found that alloying copper with other elements or implanting atoms on its surface can significantly improve its corrosion resistance. For example brass or bronze [8] are known since a long time as having quite good corrosion resistance.

1) Alloying with $\mathrm{Mg}$

It was found that alloying $\mathrm{Cu}$ with $\mathrm{Mg}(2 \mathrm{at} . \% \mathrm{Mg}$ ) can significantly reduce oxidation kinetics without increasing too much the electrical resistivity. $\mathrm{Cu}$ and $\mathrm{Mg}$ are evaporated simultaneously on a $\mathrm{Cu}$ substrate. After annealing the samples at $400^{\circ} \mathrm{C}$ during 30 minutes and then oxidized at $350^{\circ} \mathrm{C}$ in oxygen. Compared to $\mathrm{Cu}$ pure samples it was found that $\mathrm{Cu}-\mathrm{Mg}$ samples have a very thin surface oxide [9] in Figure 5 whose thickness is independent of the oxidation time. The passive film is $6 \mathrm{~nm}$ of $\mathrm{Mg}$ oxide which provides passive protection of this metal surface.

2) Ion implanted materials

Recently, it has been proved that $\mathrm{Cu}$ implanted with $\mathrm{Al}, \mathrm{N}, \mathrm{B}, \mathrm{Mg}$ or $\mathrm{Cr}$ presents quite good corrosion resistance [10]-[12]. It has also been demonstrated that the damage associated with the ion implantation can be annealed away without the loss of the passivating effect of the implantation [11]. From the oxidation process of $\mathrm{Cu}$ known that after formation of a thin $\mathrm{Cu}_{2} \mathrm{O}$ on the surface, the oxide grows by transport of $\mathrm{Cu}$ ions through this oxide film. In this transport mechanism, negatively charged vacancies in the oxide provide sites for $\mathrm{Cu}^{+}$ions diffusing through the oxide, as a result in the transport of $\mathrm{Cu}$ from the metal to the surface where it is oxidized, block the transport of $\mathrm{Cu}$ metals to the surface is the key issue's here to avoid further oxidization of $\mathrm{Cu}$. Using ion implantation process easily can do it, two related mechanisms are mainly responsible, which could influence the oxidation rate of implanted $\mathrm{Cu}$ films. First one is the implanted atoms fill the vacancies in $\mathrm{Cu}_{2} \mathrm{O}$ and hence blocks the transport paths of $\mathrm{Cu}$. Second mechanism is the presence of the implanted atoms changes the oxidation chemistry, resulting in the formation of a self-passivating oxide [11]. As a result $\mathrm{Cu}$ implanted with different elements to enhance the oxidization resistance of $\mathrm{Cu}$.

3) Brass, bronze and white bronze

White bronze are used as a protective coating [8], low cost, corrosion resistant and hard metal finish [13]. For brass reliable references are not available, but since it is possible to deposit $\mathrm{Zn}$ and $\mathrm{Sn}$ by electro deposition, the process used for Au coating and these materials to be good candidate to increase corrosion resistance and hardness of the connection pad.

\subsubsection{Tin (Sn) Plating}

Sn plating has already been investigated in order to replace Au plating [14]. But thin oxide film formed [7] at the surface can be easily broken with a minimal force, so that a low resistant contact can be established. In CES

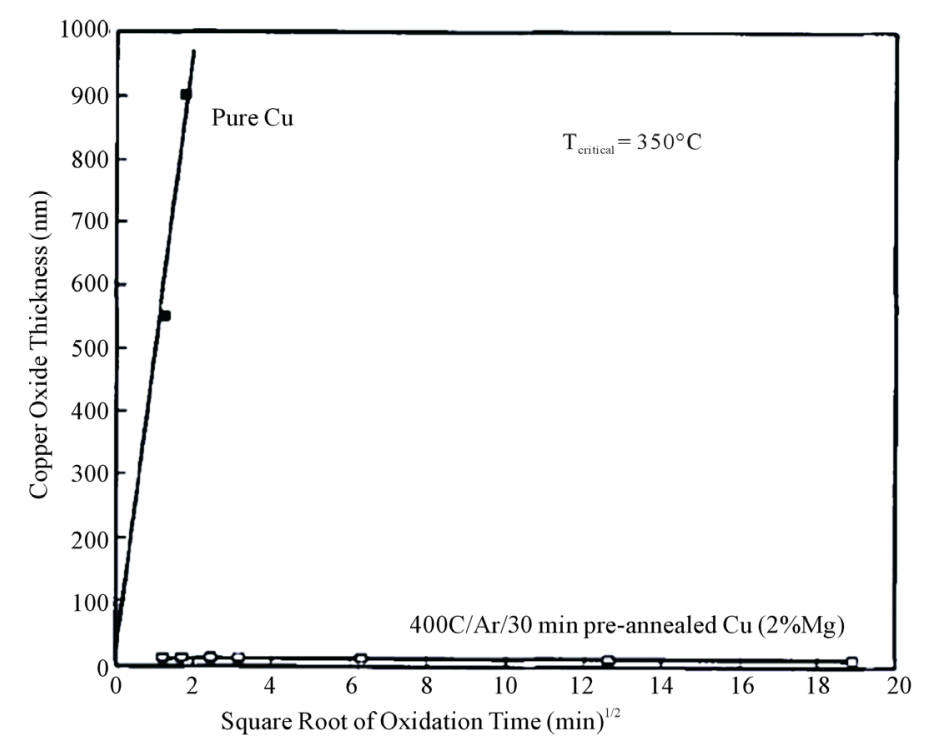

Figure 5. Oxidation kinetics of copper versus copper modified with Mg. 
study also it has been eliminated and was found Sn has unacceptable resistance to strong acids and oxidized at $500^{\circ} \mathrm{C}$. Therefore it has been decided not to keep in the list as the promising materials. However, with a deeper study of the different existing alloys of Sn, can imagine to find one which is corrosion resistant enough.

\subsubsection{Silver (Ag) and Chromium (Cr) Coating}

$\mathrm{Ag}$ was found as a possible coating on $\mathrm{Cu}$ in contact applications [15]. The cost of Ag coating is lower than the Au coating. In CES, Ag was found to have a cost higher than our limiting cost: around 400 Euros $/ \mathrm{kg}$. Therefore, even $\mathrm{Ag}$ is less costly than $\mathrm{Au}$, not to focus on it since other materials which are far less costly are available. $\mathrm{Cr}$ is known as corrosion resistance, this is the reason it was used as alloying element for stainless steel. Cr can be deposited by electroplating [16]. Therefore it is considered as a good candidate.

\subsubsection{Titanium (Ti) Compounds and Silicides}

$\mathrm{Ti}$, Ti nitride $(\mathrm{TiN})$ and boride $\left(\mathrm{TiB}_{2}\right)$ and also some silicides $\left(\mathrm{MoSi}_{2}\right)$ were found have the properties required for the coating. Indeed, they combine good electrical and mechanical properties, excellent corrosion resistance.

\section{Discussion}

Considering the required properties of coating, filtered the promising materials from simulated (CES) and bibliographical research and is given in below.

\subsection{Thickness Incompatibility Considerations}

In CES studies noted that for a given hardness there is a minimum thickness of the coating if it would be resistant against impacts. On the other hand for a given resistivity there is a maximum thickness if the electrical resistance would be of the order of a wire's resistance. If the maximum thickness imposed by the resistivity is smaller than the minimum thickness imposed by the hardness, the material will not be able to satisfy both properties at the same time. This means that the materials with a high conductivity and low hardness will not be suitable. In Figure 6, Hardness vs. electrical resistivity, it is embodied by a domain delimited by a line. The equation of this line is obtained by equalizing the minimum thickness imposed by the hardness and the maximum thickness imposed by the resistivity. From this equation hardness can be extract as a function of the resistivity.

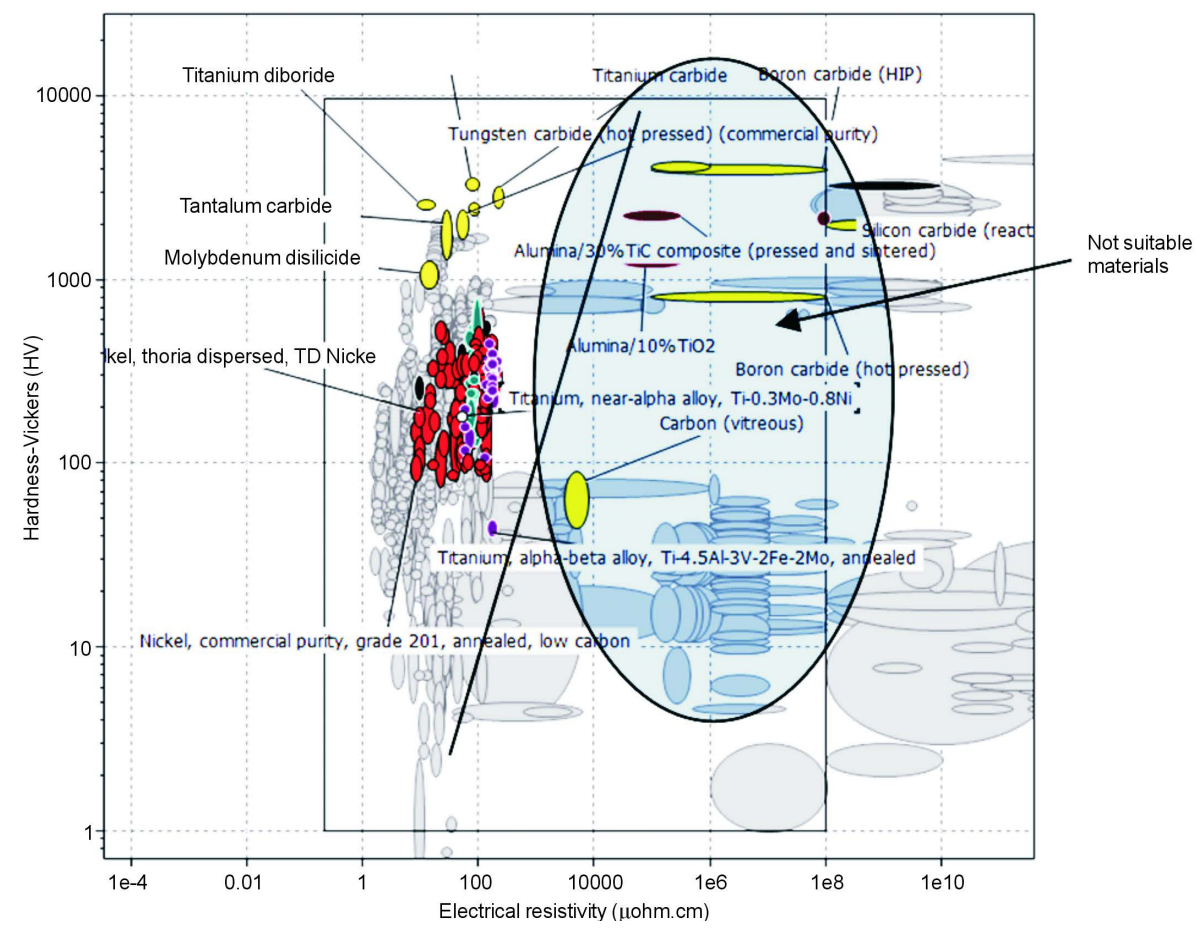

Figure 6. Hardness vs. electrical resistivity of the coating. 
Since it is well known and did not plot in CES graph. But verified one by one which materials were eliminated by this criterion. The materials (Carbon (vitreous), Alumina-TiC composite, Alumina- $\mathrm{TiO}_{2}, \mathrm{~B}$ carbide and $\mathrm{Si}$ carbide) were eliminated with the lowest curve of maximum thickness vs. resistivity (Section 2.1). If consider the higher curve, they remain in the list. But since this is a first order study, the real result of this stage would require a deeper study. Now need to eliminate these materials because even if there can stay in the list depending on which limiting values has been used, they do not have the best combination of hardness and resistivity.

\subsection{Toxicity Considerations (Ni Alloys and Cobalt)}

Since $\mathrm{Ni}$ is an allergenic material and regulations are going in the direction of its future ban, did not retained alloys based on Ni. But if the alloy use contains a small amount of Ni, it is less allergenic than a Ni-based alloy. For example, $\mathrm{Ni}$ and $\mathrm{Cu}-\mathrm{Ni}$ alloys are used nowadays in the Euros coins. Cobalt is known for its toxicity in some conditions. But, in which conditions the element is really dangerous it was not investigated. Since many possible materials were available and did not consider to keep it in the list.

\subsection{Renewable Issues}

Since smart cards are produced by billions of units in every year, it has been considered that the materials used had to be available on Earth in sufficiently high amount, and if possible be renewable resources. No figures were observed in CES concerning the availability of the different materials on Earth. But, considering the price of the material have a rough idea: rare materials are more expensive than very common ones. To reduce the limiting value of cost in CES studies was tried, in order to see which materials were able to eliminate with this criterion. If the limiting value of cost to 20 Euros/kg, very few materials ( $\mathrm{Ti}, \mathrm{TiB}_{2}, \mathrm{Cr}$, Stainless steel) are found.

\subsection{Process Discussion}

\subsubsection{Electroplating Process}

Much information about processes is available in CES. For example the hardness of the coating vs. the thickness was plotted in Figure 7. Since the Au coating in the current technology is performed with electroplating process, changing the material but keeping this process would be a first solution to investigate, because of the low cost of installation. First prototypes can be made rapidly by trying to deposit low cost material such as brass or bronze. Therefore it seems that the first direction to investigate in order to change the coating of smart cards. Most of the alloys were found can be deposited with the electroplating process: Fe, Ni, Cu, Sn, Cr, and $\mathrm{Zn}$ [17] [18]. Electroplating has the advantage of being performed at ambient temperature. $\mathrm{Cr}$ is a common material for electroplating processes and used for decorative coating as a way to protect metallic parts from corrosion and wear [19], for example in accessories like bag fasteners. But two types of technologies exist: one based on a $\mathrm{Cr}^{6+}$ solution and the other based on a $\mathrm{Cr}^{3+}$ solution. The use of $\mathrm{Cr}^{6+}$ raises safety and environmental issues [19] since the liquid and gaseous by-products of the process are highly toxic. For use this coating, need to implement it with the $\mathrm{Cr}^{3+}$ solution process.

\subsubsection{Vapour Deposition Process}

The non metallic species (TiN, $\mathrm{MoSi}_{2}$, WC, $\mathrm{TiB}_{2}$ ) which are found can be easily deposited with chemical or physical vapour deposition. PVD and CVD are quite common industrial technique and could be used in deposition process. However these are more costly than electroplating and require a high temperature which means a high energy. Since much information about the real configuration of the connection pad was unknown at the time of coating: processes are kept secret. At the time of deposition on which substrate of the connection pad was unknown and if this substrate can resist to the high temperature required in CVD. Specially, the connection pads are already finished when the chip is connected to it but somewhere found coating is applied at the end. Since, deep and reliable information about the real process is not well known, PVD or CVD process could be used for the coating: but may be the chip cannot undergo such high temperature.

\subsubsection{Ion Implantation}

The process of ion implantation is more expensive than electroplating. But using it if the properties of resulting $\mathrm{Cu}$ film are really good and if prototypes using the technology described (Section 3.2.1) happen to be working on the required lifetime can be consider this process. 


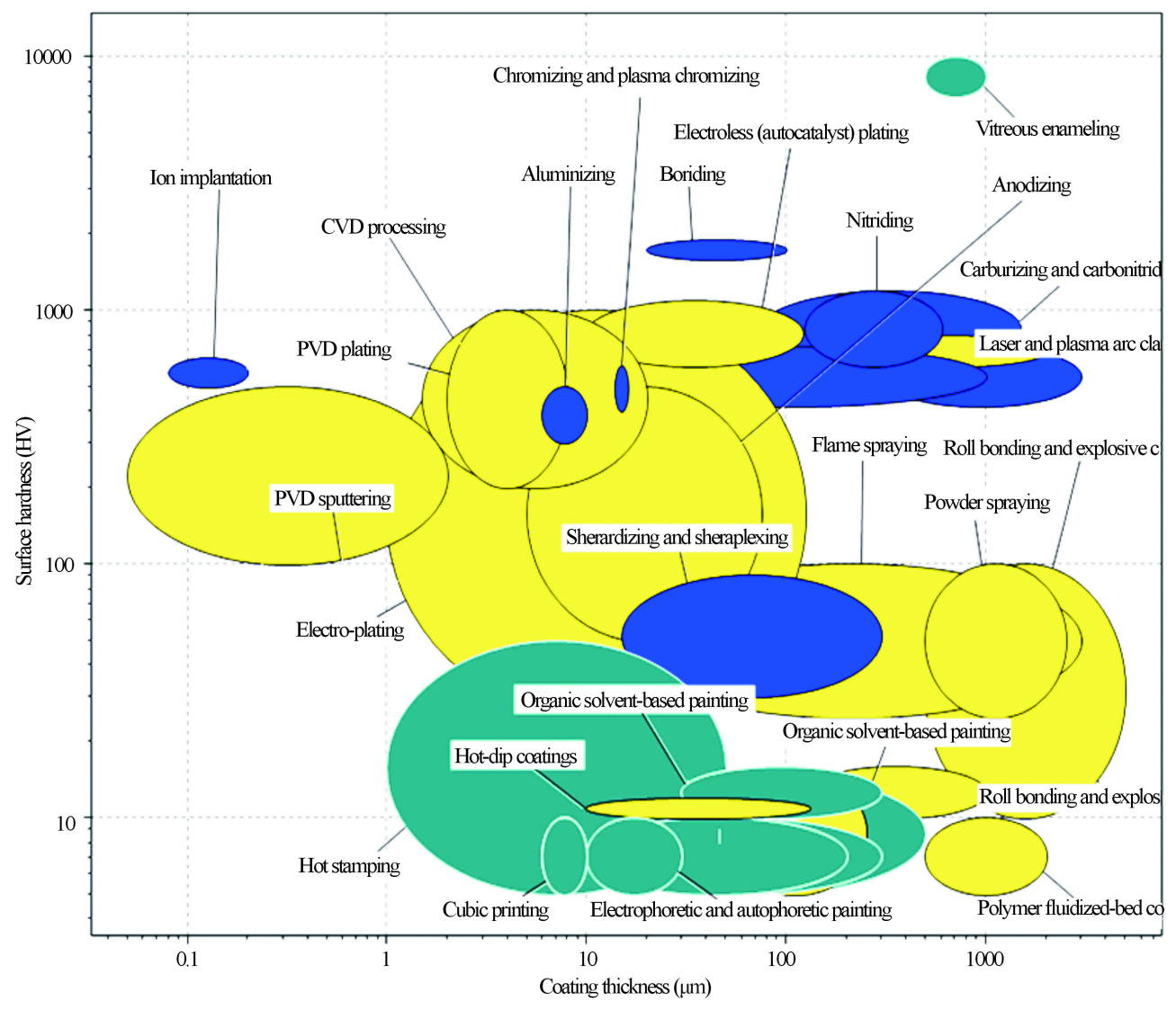

Figure 7. Hardness of the coating vs. thickness.

\section{Conclusion}

This paper investigated possible materials in order to replace the Au and Ni layer in smart card connectors. Considering the required properties of the materials which seem to be the best are $\mathrm{Cu}$ alloys such as particular brass or bronze. These materials combine indeed good mechanical and electrical properties, corrosion resistance, low cost, and availability on Earth. Moreover, the process can be used for the coating, is based on the current technology and will not represent a very high cost of investment. Therefore, implementation of such alloys in prototypes is also essential. The second possible materials were found such as $\mathrm{Ti}, \mathrm{TiN}, \mathrm{TiB}_{2}, \mathrm{MoSi}_{2}$ and some $\mathrm{Cu}$ alloying with $\mathrm{Al}, \mathrm{N}$ or $\mathrm{Mg}$. However, these materials required processes are CVD, PVD and ion implantation and performed at high temperature, which is expensive. In order to use these materials, one has to know that these processes are compatible with the frame in which the coating is performed, especially if the chip is already mounted to the connection pad at the time of the process. So, these materials could be considered in a second step, if the $\mathrm{Cu}$ based alloys (brass and bronze) and other electrodeposited elements found to be not suitable enough for enhanced application.

\section{References}

[1] Knoll, B.T. (2007) Smart Card. U.S. Patent No. 7213769B2.

[2] About Smart Cards (2014) Introduction: Market Information. http://www.smartcardalliance.org/smart-cards-intro-market-information

[3] Rankl, W. and Effing, W. (1997) Smart Card Handbook. John Willey \& Sons, Chichester.

[4] Richard, E. (2006) Microsoft PowerPoint-DS-006. Smartcard Substrate Datasheet Review [Online]. www.possehlelectronics.com/images/Smartcard.pdf

[5] Ashby, M., Shercliff, H. and Cebon, D. (2007) Materials: Engineering, Science, Processing and Design. Elsevier, Oxford. 
[6] Bausson, S. (1995) ISO7816 Asynchronous Smartcard Information [Online]. www.gae.ucm.es/ padilla/extrawork/iso7816.txt

[7] Lee, K.Y., Jeong, D.K. and Kim, J.H. (2011) Simulational Study of Electrical Contact Degradation under Fretting Corrosion. Tribology International, 44, 1651-1658. http://dx.doi.org/10.1016/j.triboint.2011.06.008

[8] Lalanne, P. (2006) Utilisation du bronze blanc sur les produits portés externs. Matériaux \& Techniques, 94, 39-45. http://dx.doi.org/10.1051/mattech:2006023

[9] Ding, P.J., Lanford, W.A., Hymes, S. and Murarka, S.P. (1994) Oxidation Resistant High Conductivity Copper Films. Applied Physics Letters, 64, 2897-2899. http://dx.doi.org/10.1063/1.111408

[10] An, Q.Z., Li, L.H., Hu, T., Xin, Y.C., Fu, R.K.Y., Kwok, D.T.K., Cai, X. and Chu, P.K. (2009) Comparison of Oxidation Resistance of Copper Treated by Beam-Line Ion Implantation and Plasma Immersion Ion Implantation. Materials Chemistry and Physics, 16, 519-522. http://dx.doi.org/10.1016/j.matchemphys.2009.04.023

[11] Ding, P.J., Wang, W., Lanford, W.A., Hymes, S. and Murarka, S.P. (1994) Investigation of the Mechanism Responsible for the Corrosion Resistance of B Implanted Copper. Nuclear Instruments and Methods in Physics Research, 85, 260-263. http://dx.doi.org/10.1016/0168-583X(94)95823-8

[12] Zhao, X.Q., Han, Y.F. and Liu, B.X. (2001) Modification of Oxidation Resistance of Copper Films by Shallow Implantation. Journal of Applied Physics, 90, 1638-1641. http://dx.doi.org/10.1063/1.1379774

[13] DePoto, R.E., Grunewald, A., Weber, J. and Leyendecker, K. (2013) White Bronze, Copper-Tin-Zinc Tri-Metal: Expanding Applications and New Developments in a Changing Landscape, Products Finishing.

[14] Evans, C. (1980) Connector Finishes: Tin in Place of Gold. IEEE Transactions on Components, Hybrids, and Manufacturing Technology, 3, 226-232. http://dx.doi.org/10.1109/TCHMT.1980.1135606

[15] Rudolphi, A.K. and Jacobson, S. (1997) Stationary Loading, Fretting and Sliding of Silver Coated Copper ContactInfluence of Corrosion Films and Corrosive Atmosphere. Tribology International, 30, 165-175. http://dx.doi.org/10.1016/S0301-679X(96)00031-X

[16] Mandich, N.V. and Snyder, D.L. (2010) Electrodeposition of Chromium, Modern Electroplating. John Willey \& Sons, Hoboken.

[17] Izaki, M. (2010) Electrodeposition of Iron and Iron Alloys, Modern Electroplating. John Willey \& Sons, Hoboken, 309-326.

[18] Schlesinger, M. and Paunovic, M. (2010) Modern Electroplating. John Willey \& Sons, Hoboken. http://dx.doi.org/10.1002/9780470602638

[19] Snyder, N.V., Dans, M.P. and Schlesinger, M. (2010) Electro Deposition of Chromium: Modern Electroplating. John Willey \& Sons, Hoboken, 205-248. 